\title{
Treatment outcomes among HIV-positive orphaned and non-orphaned children on antiretroviral therapy in Johannesburg, South Africa
}

C Hendrickson, ${ }^{1}$ MPH; D Evans, ${ }^{1}$ PhD; A T Brennan, ${ }^{1,2}$ PhD; S Patz, ${ }^{3}$ MB BCh; S Untiedt, ${ }^{4}$ MB ChB, MSc (Med) Pharm, Dip HIV Man (SA); J Bassett, ${ }^{5} \mathrm{MB}$ BCh; L Levin, ${ }^{4} \mathrm{MB}$ BCh, FCPaed (SA), DTM\&H; I Sanne, ${ }^{1,4,6}$ MB BCh, FCP (SA), FRCP (Lond), DTM\&H; M P Fox, ${ }^{1,2,7}$ DSc

\author{
${ }^{1}$ Health Economics and Epidemiology Research Office, Department of Internal Medicine, Faculty of Health Sciences, University of the \\ Witwatersrand, Johannesburg, South Africa \\ ${ }^{2}$ Department of Global Health, Boston University School of Public Health, Boston, Mass, USA \\ ${ }^{3}$ Alexandra Health Centre and University Clinic, Johannesburg, South Africa \\ ${ }^{4}$ Right to Care, Johannesburg, South Africa \\ ${ }^{5}$ Witkoppen Health and Welfare Centre, Johannesburg, South Africa \\ ${ }^{6}$ Clinical HIV Research Unit, Department of Internal Medicine, Faculty of Health Sciences, University of the Witwatersrand, Johannesburg, \\ South Africa \\ Department of Epidemiology, Boston University School of Public Health, Boston, Mass, USA
}

Corresponding author: C Hendrickson (chendrickson@heroza.org)

Background. Limited research investigating treatment outcomes for HIV-positive orphans compared with non-orphans has shown mixed results, with several studies indicating that HIV-positive orphans are at greater risk of delayed access to HIV care and poor antiretroviral therapy (ART) adherence, while other data suggest that ART outcomes of orphans can be similar to those of non-orphans. Understanding the impact of orphan status on short-term ART outcomes could improve targeted intervention strategies, and subsequent long-term treatment and developmental outcomes, for HIV-positive infants, children and adolescents.

Objectives. To evaluate the relationship between orphan status and ART outcomes among HIV-positive infants, children and adolescents initiating ART at two large public sector HIV clinics in Johannesburg, South Africa.

Methods. This was a retrospective cohort study of HIV-positive children aged $<18$ years initiating standard first-line ART between June 2004 and May 2013. Using propensity scores, orphans and non-orphans were matched for age, sex, World Health Organization stage and ART regimen. The effect of orphanhood on attrition from care (all-cause mortality and loss to follow-up) was evaluated using Cox proportional hazards regression analysis, and its effect on having a detectable viral load ( $\geq 400 \mathrm{copies} / \mathrm{mL})$ at 12 months on ART using binomial regression analysis with modified Poisson distribution.

Results. A total of 251 (29.4\%) orphans (maternal, paternal or both) and 603 (70.6\%) non-orphans were included at ART initiation. Following multiple imputation for missing data and propensity score matching, 222 orphans and 222 non-orphans were included. Orphans had a median age of 8.0 years (interquartile range (IQR) 4.9 - 10.7) and non-orphans 7.4 years (IQR 4.2 - 10.2). A total of 12 (5.4\%) orphans and 33 (14.9\%) non-orphans experienced attrition from care during the first 12 months on ART (adjusted hazard ratio 0.32 , 95\% confidence interval (CI) 0.17 - 0.63). Among those alive and in care, with a viral load at 12 months on ART, $18.0 \%$ of orphans (33/183) and $14.8 \%$ of non-orphans (24/162) had a detectable viral load (adjusted risk ratio $1.15,95 \%$ CI $1.04-1.28$ ).

Conclusions. Orphans were less likely than non-orphans to experience attrition, but among those in care at 12 months, orphans were more likely to have detectable viral loads. Lower attrition among orphans may be due to their being in institutional or foster care, ensuring that they make their visits; however, their higher rates of non-suppression may result from lack of psychosocial support or stigma resulting in struggles to adhere. Additional research investigating age-specific outcomes will be important to elucidate these effects further.

S Afr Med J 2019;109(9):679-685. https://doi.org/10.7196/SAMJ.2019.v109i9.13462

Worldwide, $\sim 17.8$ million children are estimated to have lost one or both parents due to HIV/AIDS. ${ }^{[1]}$ In South Africa (SA) alone there are an estimated 3.9 million orphans, almost half of whom have lost one or both parents to AIDS-related diseases. ${ }^{[2]}$ In 2012 the prevalence of orphanhood in SA was estimated at 16.9\%, with orphans 3.5 times more likely to be HIV-positive compared with non-orphans. ${ }^{[3]}$ With an estimated 320000 children living with HIV in 2016, SA has the largest paediatric antiretroviral therapy (ART) programme in the world. ${ }^{[4]}$

Previous research indicates that social vulnerabilities including poverty, poor access to education, homelessness, neglect and abuse may result in orphans experiencing substantial barriers to accessing healthcare, leading to poorer treatment and developmental outcomes. ${ }^{[5-11]}$ Furthermore, HIV-positive orphans have been shown to be at increased risk of delayed access to HIV care and poor ART adherence. ${ }^{[5,12-15]}$ However, some limited data suggest that ART outcomes of orphans can be similar to those of non-orphans. ${ }^{[16-18]}$ Given the high burden of combined HIV and orphanhood in SA, these are important problems to investigate but complicated ones to address, partly because orphans are such a vulnerable and difficult population to reach.

\section{Objectives}

To evaluate the association between orphan status (v. non-orphaned, matched on baseline characteristics) at ART initiation with attrition 
from care and viral suppression at 12 months among a sample of HIV-positive infants, children and adolescents attending two large public sector HIV clinics in Johannesburg, SA.

\section{Methods}

We conducted a retrospective analysis of prospectively collected data from two paediatric primary healthcare clinics in Johannesburg. Both sites are public sector clinics that follow the national ART treatment guidelines. ${ }^{[19-21]}$ All HIV-positive ART-naive infants, children and adolescents aged $<18$ years who initiated a standard first-line ART regimen between 1 June 2004 and 31 May 2013 were included. Demographic and clinical information was captured using an electronic patient management system (TherapyEdge-HIV; Advanced Biological Laboratories (ABL) S.A., Luxembourg), while laboratory data were uploaded directly into TherapyEdge-HIV from the South African National Health Laboratory Service on a daily basis. To supplement data from electronic medical records, hard copies of patient medical files were reviewed.

According to the United Nations Children's Fund (UNICEF) definition, an orphan is classified as a child aged $<18$ years who has lost one or both parents to any cause of death, while a double orphan is one who has lost both parents. ${ }^{[22]}$ Baseline orphan status was defined as a child who had lost one or both parents prior to, or up to 6 months after, the date of ART initiation. A 6-month window after ART initiation was used to allow for passive follow-up and patient tracing or reporting of parent death. For the purpose of this analysis, the exposures of orphan v. non-orphan were considered. We used multiple imputation by chained equations to impute missing baseline values in our dataset. Baseline demographic and clinical characteristics of all patients were summarised and stratified by baseline orphan status, and we determined the association between these factors and being classified as an orphan using logistic regression analysis. Adjusted odds ratios with the corresponding 95\% confidence intervals (CIs) are presented, and predictor variables (e.g. sex, age, nationality, year of ART initiation, baseline CD4+ count/percentage, World Health Organization (WHO) stage, tuberculosis, anaemia, weight, height, ART regimen and facility) were used to create a propensity score
(Supplementary Table 1, available at http://www.samj.org.za/public/ sup/13462_table.pdf). Researchers then matched each orphan with one potential non-orphan using propensity score matching, within facility, using a Mayo Clinic SAS macro. ${ }^{[23]}$ As orphans and nonorphans were substantially different, particularly with regard to age at initiation (the median age for orphans and non-orphans was 8.5 years (interquartile range (IQR) 5.1 - 11.5) and 2.9 years (IQR 1.0 7.4), respectively), greedy matching with a difference of 0.2 was used. Baseline CD4+ count, CD4+ percentage, haemoglobin, WHO stage and weight were assigned as the measurement date closest to the date of ART initiation within 90 days before and 7 days after treatment start date. Table 1 defines the immunological, disease and growth categories at ART initiation.

Outcomes by 12 months on ART included: (i) attrition, a composite outcome of all-cause mortality and loss to follow-up (LTF); and (ii) failure to suppress viral load. Deaths were identified by the family or by medical record review, and/or linkage with the SA national vital registration system. ${ }^{[2]]} \mathrm{LTF}$ was defined as at least 3 months late for the last scheduled visit. Person-time accrued from ART initiation until the earliest of: ( $i$ ) outcome of interest; (ii) transfer; (iii) completion of 12 months of follow-up; or (iv) dataset closure on 31 May 2014, at which point person-time was censored. Cox proportional hazards models, clustered by facility, were used to evaluate the relationship between orphanhood and attrition.

Failure to suppress viral load at 12 months was defined as having a detectable viral load ( $>400$ copies $/ \mathrm{mL}$ ) at 12 months after ART initiation. ${ }^{[25]}$ To allow for variation in visit timing, for patients who were alive and in care at 12 months after ART initiation, the viral load closest to 12 months ( \pm 6 months) was used in the analysis. To evaluate the association between orphan status and a detectable viral load at 12 months on ART, researchers used binomial regression analysis with a modified Poisson distribution, clustered by facility. Proportions and relative rates (RRs) of virological suppression were calculated among those alive and in care, with a viral load at 12 months on ART,

Ethical approval was provided by the Human Research Ethics Committee (Medical) of the University of the Witwatersrand (ref.

Table 1. Adjusted WHO categorisations of immunosuppression, staging, ${ }^{\star}$ anaemia and growth standards

\begin{tabular}{|c|c|c|c|c|}
\hline Immunosuppression ${ }^{\dagger}$ & Not significant & Mild & Advanced & Severe \\
\hline Up to 12 months of age (CD4+ percentage) & $>35$ & $25-34$ & $20-24$ & $<20$ \\
\hline$\geq 12$ - 59 months of age (CD4+ percentage) & $>25$ & $20-24$ & $15-19$ & $<15$ \\
\hline$\geq 5$ years of age $(\mathrm{CD} 4+$ cells $/ \mu \mathrm{L})$ & $>500$ & $350-499$ & $200-349$ & $<200$ \\
\hline Anaemia (haemoglobin, g/dL) $)^{\ddagger}$ & No anaemia & Mild & Moderate & Severe \\
\hline 0 - 6 months of age & No data & No data & No data & No data \\
\hline 6 - 59 months of age & $\geq 11.0$ & $10.0-10.9$ & $7.0-9.9$ & $<7.0$ \\
\hline 5 - 11 years of age & $\geq 11.5$ & $11.0-11.4$ & $8.0-10.9$ & $<8.0$ \\
\hline $12-14$ years of age & $\geq 12.0$ & $11.0-11.9$ & $8.0-10.9$ & $<8.0$ \\
\hline Females $\geq 15$ years of age & $\geq 12.0$ & $11.0-11.9$ & $8.0-10.9$ & $<8.0$ \\
\hline Males $\geq 15$ years of age & $\geq 13.0$ & $11.0-12.9$ & $8.0-10.9$ & $<8.0$ \\
\hline Weight for age $^{\S}$ & Normal & Undernourished & \multicolumn{2}{|c|}{ Severely undernourished } \\
\hline$\leq 5$ years of age $(z$-score $)$ & $\geq 2 \mathrm{SD}$ & $<-2$ SD & $<-3 \mathrm{SD}$ & \\
\hline BMI for age ${ }^{\S}$ & Overweight & Obese & Thinness & Severe thinness \\
\hline $5-19$ years of age ( $z$-score) & $>+1 \mathrm{SD}$ & $>+2 \mathrm{SD}$ & $<-2 \mathrm{SD}$ & $<-3 \mathrm{SD}$ \\
\hline
\end{tabular}


no. M110140) and the Boston University Institutional Review Board (ref. no. H-29768).

\section{Results}

A total of 1332 children and adolescents were enrolled on ART during the study period, of whom 269 did not fit the inclusion criteria and 209 had unknown baseline orphan status - these were excluded, resulting in a prematched dataset of 854 patients (603 non-orphans and 251 orphans, Fig. 1). Propensity score matching using predictor variables resulted in 222 orphans being matched with 222 non-orphans, with a similar age distribution between the two groups (Table 2 and Supplementary Fig. 1 Supplementary Fig. 1 is available at http:// www.samj.org.za/public/sup/13462_table. pdf). Patients contributed 421 years of person-time during the 12-month followup period (orphans 217, non-orphans 204, Table 3$)$. The majority ( $94.6 \%$ of orphans, $85.1 \%$ of non-orphans) were still on ART after 12 months, but 12 orphans (5.4\%) and 33 non-orphans (14.9\%) were lost to care (died or LTF).

In crude Cox proportional hazard models (cHR), orphans had a reduced risk of attrition after 12 months on ART compared with non-orphans (cHR 0.32, 95\% CI 0.17 0.63) (Table 4). The time period of ART initiation also appeared to have an effect on attrition, with those who initiated ART during the later years being at a reduced risk of 12-month attrition (cHR 0.09, 95\% CI 0.01 - 0.79 for June 2012 - May 2013 compared with June 2004 - May 2006). In a model adjusted for period of ART initiation (>10\% change in estimate), baseline CD4+ and anaemia (under-matching), orphans were still less likely to experience attrition (adjusted hazard ratio 0.32, 95\% CI 0.17 $0.63)$.

Among those alive and in care, with a viral load at 12 months on ART $(77.7 \%, 345 / 444)$, $18.0 \%$ of orphans $(33 / 183)$ and $14.8 \%$ of non-orphans $(24 / 162)$ had a detectable viral load ( $>400$ copies $/ \mathrm{mL}$ ). This did not differ by age group $(p=0.7365)$. Crude analysis showed that orphans had an increased risk of a detectable viral load at 12 months after initiation of ART compared with non-orphans (crude risk ratio (cRR) 1.22, 95\% CI 1.12 - 1.32, Table 4). Additionally, those with a high or moderate CD4+ count/ percentage at baseline were $74 \%$ and $26 \%$ more likely to have a detectable viral load at 12 months, respectively, compared with those with a very low baseline CD4+. Those at WHO stage III/IV at ART initiation were

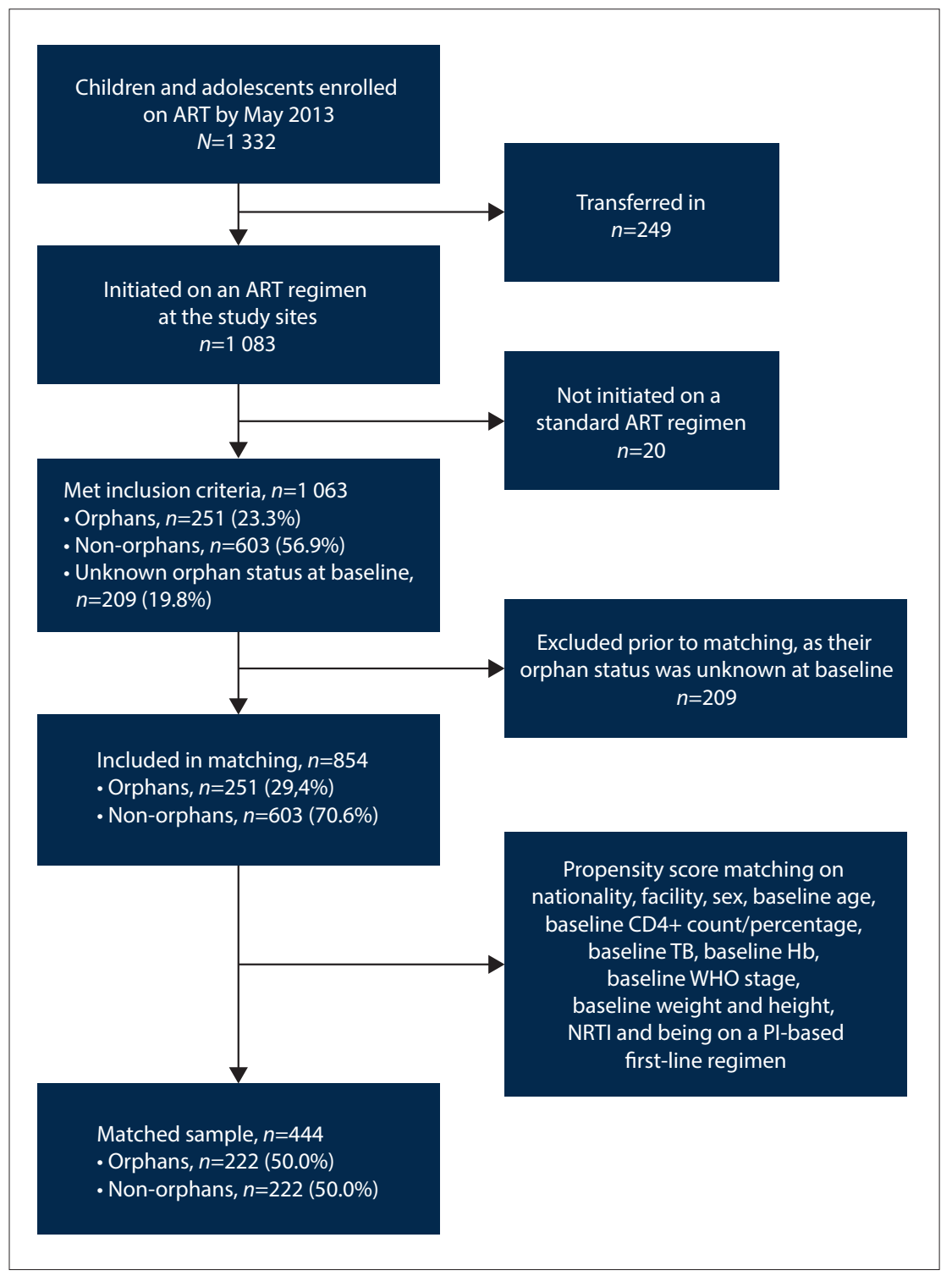

Fig. 1. Cohort profile of children and adolescents initiating ART at one of two study sites in Johannesburg, $S A .(A R T=$ antiretroviral therapy; $S A=$ South Africa; $T B=$ tuberculosis; $H b=$ haemoglobin $; W H O=$ World Health Organization; NRTI = nucleoside reverse transcriptase inhibitor; $P I=$ protease inhibitor.)

less likely to have a detectable viral load compared with those at WHO stage I/II (cRR $0.74,95 \%$ CI 0.64 - 0.87). Similarly, those with below-normal baseline anthropometric measurements had a lower risk of having a detectable viral load at 12 months than those with normal measurements (cRR 0.67, 95\% CI 0.47 - 0.95). Compared with those who initiated ART on a non-stavudine-based regimen, those who initiated on a stavudinebased regimen were less likely to have a detectable viral load at 12 months after ART initiation (cRR 0.48, 95\% CI $0.39-0.59$ ). Similarly, patients who initiated ART in the later years of the study were less likely to have a detectable viral load compared with those who initiated ART in the first 2 years. Lastly, in crude analyses, patients were $45 \%$ less likely to have a detectable viral load at site B compared with site A. In a model adjusted for tuberculosis at ART initiation (>10\% in effect estimate), baseline CD4+ and anaemia (under-matching), baseline WHO stage, anthropometric measurements and facility (significant in crude analyses), orphans were still more likely to have a detectable viral load at 12 months on ART (adjusted risk ratio (aRR) 1.15, 95\% CI 1.04 1.28 ), with participants at site B less likely to do so than those at site A (aRR 0.75, 95\% CI $0.61-0.94$ ).

\section{Discussion}

In this matched cohort of 444 infants, children and adolescents in SA, we observed that $5.4 \%$ of orphans and $14.9 \%$ of non- 


\begin{tabular}{|c|c|c|}
\hline & Non-orphans $(N=222)$ & Orphans $(N=222)$ \\
\hline \multicolumn{3}{|l|}{ Sex, $n(\%)$} \\
\hline Female & $115(51.8)$ & $110(49.6)$ \\
\hline Male & $107(48.2)$ & $112(50.5)$ \\
\hline \multicolumn{3}{|l|}{ Age at initiation (years), $n$ (\%) } \\
\hline$\leq 1$ & $9(4.1)$ & $11(5.0)$ \\
\hline$>1-\leq 5$ & $58(26.1)$ & $50(22.5)$ \\
\hline$>5-\leq 10$ & $95(42.8)$ & $99(44.6)$ \\
\hline$>10$ & $60(27.0)$ & $62(27.9)$ \\
\hline \multicolumn{3}{|l|}{ Time period of ART initiation, $n(\%)$} \\
\hline June 2004 - May 2006 & $12(5.4)$ & $15(6.8)$ \\
\hline June 2006 - May 2008 & $48(21.6)$ & $45(20.3)$ \\
\hline June 2008 - May 2010 & $72(32.4)$ & $74(33.3)$ \\
\hline June 2010 - May 2012 & $60(27.0)$ & $65(29.3)$ \\
\hline June 2012 - May 2013 & $30(13.5)$ & $23(10.4)$ \\
\hline \multicolumn{3}{|l|}{$\mathrm{CD} 4+$ measurement $^{*}$ at ART initiation, $n(\%)$} \\
\hline Severe & $95(42.8)$ & $85(38.3)$ \\
\hline Advanced & $51(23.0)$ & $56(25.2)$ \\
\hline Mild & $28(12.6)$ & $35(15.8)$ \\
\hline Not significant & $48(21.6)$ & $46(20.7)$ \\
\hline \multicolumn{3}{|l|}{ WHO clinical stage at ART initiation, $n(\%)$} \\
\hline I or II & $138(62.2)$ & $145(65.3)$ \\
\hline III or IV & $84(37.8)$ & $77(34.7)$ \\
\hline \multicolumn{3}{|l|}{ TB at ART initiation, $n(\%)$} \\
\hline Yes & $45(20.3)$ & $44(19.8)$ \\
\hline No & $177(79.7)$ & $178(80.2)$ \\
\hline \multicolumn{3}{|l|}{ Anaemia at ART initiation, $n(\%)$} \\
\hline None & $79(35.6)$ & $95(42.8)$ \\
\hline Mild & $47(21.2)$ & $45(20.3)$ \\
\hline Moderate/severe & $96(43.2)$ & $82(36.9)$ \\
\hline \multicolumn{3}{|l|}{ Weight for age at ART initiation, $n(\%)$} \\
\hline Normal (WAZ $\geq-2$ SD) & $51(76.1)$ & $48(78.7)$ \\
\hline Undernourished (WAZ $<-2$ to $\geq-3 \mathrm{SD}$ ) & $9(13.4)$ & $8(13.1)$ \\
\hline Severely undernourished (WAZ $<-3$ SD) & $5(7.5)$ & $5(8.2)$ \\
\hline Missing & $2(3.0)$ & $0(00)$ \\
\hline \multicolumn{3}{|l|}{ BMI for age at ART initiation, $n(\%)$} \\
\hline Overweight or obese (ZBA >1 SD) & $7(4.5)$ & $8(5.0)$ \\
\hline Normal weight (ZBA -2 to 1 SD) & $68(43.9)$ & $64(39.8)$ \\
\hline Thinness (ZBA $<-2$ SD) & $14(9.0)$ & $18(11.2)$ \\
\hline Severe thinness $(\mathrm{ZBA}<-3 \mathrm{SD})$ & $29(18.7)$ & $36(22.4)$ \\
\hline Missing & $37(23.9)$ & $35(21.7)$ \\
\hline \multicolumn{3}{|l|}{ Baseline ART regimen, $n(\%)$} \\
\hline \multicolumn{3}{|l|}{ NRTI } \\
\hline $\mathrm{ABC}$ & $80(36.0)$ & $76(34.2)$ \\
\hline TDF & $6(2.7)$ & $4(1.8)$ \\
\hline $\mathrm{d} 4 \mathrm{~T}$ & $136(61.3)$ & $142(64.0)$ \\
\hline \multicolumn{3}{|l|}{$\mathrm{PI}^{\dagger}$} \\
\hline No & $201(90.5)$ & $195(87.8)$ \\
\hline Yes & $21(9.5)$ & $27(12.2)$ \\
\hline \multicolumn{3}{|l|}{ Site, $n(\%)$} \\
\hline Site A & $35(15.8)$ & $35(15.8)$ \\
\hline Site B & $187(84.2)$ & $187(84.2)$ \\
\hline
\end{tabular}


Table 2. (continued) Clinical and demographic characteristics at ART initiation stratified by orphan status in HIV-positive children and adolescents initiating ART in Johannesburg, SA, after propensity score matching $(N=444)$

\begin{tabular}{|c|c|c|}
\hline & Non-orphans $(N=222)$ & Orphans $(N=222)$ \\
\hline Age at ART initiation (years), median (IQR) & $7.4(4.2-10.2)$ & $8.0(4.9-10.7)$ \\
\hline CD4+ absolute count ${ }^{\ddagger}($ cells $/ \mu \mathrm{L})$ at ART initiation, median (IQR) & $258(127-511)$ & $274(126-465)$ \\
\hline CD4+ percentage ${ }^{*}(\%)$ at ART initiation, median (IQR) & $16.8(13.0-19.8)$ & $15.5(11.7-21.9)$ \\
\hline Haemoglobin (g/dL) at ART initiation, median (IQR) & $10.9(9.9-11.8)$ & $11.2(10.3-12.0)$ \\
\hline Weight for age ${ }^{\S}$ at ART initiation ( $z$-score), median (IQR) & $-1.1(-1.9--0.6)$ & $-1.1(-1.9--0.2)$ \\
\hline BMI for age ${ }^{\S}$ at ART initiation ( $z$-score), median (IQR) & $-1.3(-2.9--0.5)$ & $-1.6(-3.2--0.3)$ \\
\hline
\end{tabular}

$\mathrm{ART}=$ antiretroviral therapy; $\mathrm{SA}=$ South Africa; $\mathrm{WHO}=$ World Health Organization; $\mathrm{TB}=$ tuberculosis; $\mathrm{WAZ}=$ weight-for-age $z$-score; $\mathrm{BMI}=$ body mass index; $\mathrm{ZBA}=\mathrm{BMI}$-for-age $z$-score; $\mathrm{SD}=$ standard deviation; $\mathrm{NRTI}=$ nucleoside reverse transcriptase inhibitor; $\mathrm{ABC}=$ abacavir; $\mathrm{TDF}=$ tenofovir; $\mathrm{d} 4 \mathrm{~T}=$ stavudine; $\mathrm{PI}=$ protease inhibitor; $\mathrm{LPV} / \mathrm{r}=$ lopinavir/ritonavir $\mathrm{IQR}=$ interquartile range.

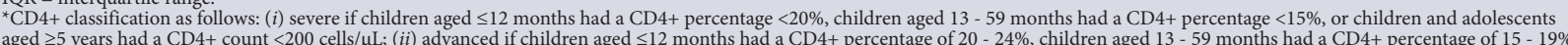
aged $\geq 5$ years had a CD4+ count $<200$ cells $/ \mu \mathrm{L}$; (ii) advanced if children aged $\leq 12$ months had a CD4+ percentage of $20-24 \%$, children aged $13-59$ months had a CD $4+$ percentage of $15-19 \%$,
or children and adolescents aged $\geq 5$ years had a CD4+ count of $200-349$ cells/ $\mu \mathrm{L}$; (iii) mild if children aged $\leq 12$ months had a CD4 percentage of $25-34 \%$, children aged $13-59$ months had a CD $4+$ percentage of $20-24 \%$, or children and adolescents aged $\geq 5$ years had a CD $4+$ count of $350-499$ cells $/ \mu \mathrm{L}$; and $(\mathrm{iv}$ ) not significant if children aged $\leq 12$ months had a CD $4+$ percentage $>35 \%$, children aged $13-59$ months had a CD $4+$ percentage $>25 \%$, or children and adolescents aged $\geq 5$ years had a CD $4+$ count $>500$ cells $/ \mu \mathrm{L}$. ${ }^{\dagger} \mathrm{PI}$ for all was LPV/r.

${ }^{\ddagger} \mathrm{CD} 4+$ percentage was calculated for children aged $<5$ years, and $\mathrm{CD} 4+$ absolute count for children and adolescents aged $\geq 5$ years.

'Weight for age was calculated for children aged $\leq 5$ years, and BMI for age for children and adolescents aged $>5$ years.

Table 3. Retention, attrition and immunological status at ART initiation stratified by orphan status in HIV-positive children and adolescents of all ages initiating ART in Johannesburg, $\mathrm{SA}$, after propensity score matching $(N=444)$

\begin{tabular}{|c|c|c|c|}
\hline & Total $(N=444), n / N(\%)$ & Orphans $(N=222), n / N(\%)$ & Non-orphans $(N=222), n / N(\%)$ \\
\hline Person-time contributed (years) & 421 & 217 & 204 \\
\hline Alive in care at 12 months on ART & $399 / 444(89.9)$ & $210 / 222(94.6)$ & $189 / 222(85.1)$ \\
\hline Viral load suppressed $d^{*, \dagger}$ & $288 / 345(83.5)$ & $150 / 183(82.0)$ & $138 / 162(85.2)$ \\
\hline Viral load not suppressed ${ }^{*, \dagger}$ & $57 / 345(16.5)$ & $33 / 183(18.0)$ & $24 / 162(14.8)$ \\
\hline Died & $6 / 444(1.4)$ & $1 / 222(0.5)$ & $5 / 222(2.3)$ \\
\hline LTF & $39 / 444(8.8)$ & $11 / 222(5.0)$ & $28 / 222(12.6)$ \\
\hline Attrition & $45 / 444(10.1)$ & $12 / 222(5.4)$ & $33 / 222(14.9)$ \\
\hline
\end{tabular}

orphans had either died or been LTF, while $18.0 \%$ of orphans and $14.8 \%$ of non-orphans alive and in care after 12 months on ART had a detectable viral load. With regard to retention in care, orphans fared better than their non-orphan counterparts, with orphans having a $68 \%$ reduction in attrition. However, among those still in care at 12 months, orphans were $15 \%$ more likely than non-orphans to have a detectable viral load.

Data on outcomes of HIV-positive orphans v. non-orphans are sparse, with mixed results. Orphan status was not associated with death in a study in Kenya, while research in India concluded that orphans did not have worse outcomes than non-orphans. ${ }^{[16,17]}$ Furthermore, a multicountry study in Asia found that post-ART mortality and retention did not differ by orphan status. However, orphans were at a greater risk of starting ART at older ages, and with more severe immunosuppression and poor growth. ${ }^{[18]}$ Similar to our results, a Cambodian study reported that orphans had an increased risk of virological failure compared with non-orphans; the authors reflected that this worse outcome was likely to be due to poor adherence, which may well be the case in the present study ${ }^{[26]}$ As we did not measure adherence, we cannot state this with certainty; however, studies in Kenya and Rwanda have shown that double orphans are at higher risk of non-adherence to ART compared with single orphans and non-orphans. ${ }^{[12,16]}$

Prior to matching, and similar to other studies, orphans initiating ART were clinically different to non-orphans, with orphans presenting at an older age as well as being slightly healthier than non-orphans, probably because they were older. ${ }^{[14,16-18]}$ Reasons for late presentation for clinical care may include parental illness delaying care-seeking for children, and that stigma around parental health and death could result in reluctance to access healthcare for the whole family. Parental death may also delay care owing to new caregivers not knowing the child's HIV status, or the general chaos of family transitions. ${ }^{[27]}$ Survey data that looked at both orphanhood and co-residence with a chronically ill or HIV-positive adult offer insight into possible reasons for these results. ${ }^{[27,28]}$ The researchers hypothesise that part of the explanation for orphans doing better than non-orphans lies in the possibility that some of the orphans are in residential or alternative care settings. ${ }^{[28]}$ Orphans are more likely than non-orphans to be in formalised care and this may lead to better retention; however, it is difficult to hypothesise why retention might be improved, but viral suppression is worse. Further work should be done to investigate outcomes of orphans in formal care settings compared with those who are non-institutionalised.

\section{Study limitations}

Our study has several limitations. Firstly, the fact that baseline orphan status was collected retrospectively, while other clinical data were collected prospectively, may have resulted in some misclassification. Twenty percent of patients who did not have baseline orphan status were excluded, and it is possible that documentation of orphan status was better among orphans who were healthier or getting better care. This potential bias was mitigated by reviewing the entire medical record and corroborating orphans' status at baseline with caregiver records throughout the file. Our data also did not include detailed information on the primary caregivers of the children and adolescents (including their HIV status), children's nutritional status, height for age, ART adherence and indicators of socioemotional or cognitive development, which may have helped in 
Table 4. Unadjusted and adjusted estimates of the relation between baseline orphan status and attrition (all-cause mortality and LTF) and viral suppression at 12 months on ART

\begin{tabular}{|c|c|c|c|c|}
\hline \multirow[b]{2}{*}{ Characteristic } & \multicolumn{2}{|c|}{ Attrition $(N=444)$} & \multicolumn{2}{|c|}{ Failure to suppress viral load ${ }^{\star}(N=345)$} \\
\hline & $n / N(\%)$ & aHR $(95 \% \mathrm{CI})$ & $n / N(\%)$ & aRR $(95 \% \mathrm{CI})$ \\
\hline \multicolumn{5}{|l|}{ Orphan status at initiation } \\
\hline Non-orphan & $33 / 222(14.9)$ & 1.00 & $24 / 162(14.8)$ & 1.00 \\
\hline Orphan & $12 / 222(5.4)$ & $0.32(0.17-0.63)$ & $33 / 183(18.0)$ & $1.15(1.04-1.28)$ \\
\hline \multicolumn{5}{|l|}{ Sex } \\
\hline Female & $23 / 225(10.2)$ & & $29 / 173(16.8)$ & \\
\hline Male & $22 / 219(10.1)$ & & $28 / 172(16.3)$ & \\
\hline \multicolumn{5}{|l|}{ Age at initiation (years) } \\
\hline$\leq 1$ & $1 / 20(5.0)$ & & $4 / 18(22.2)$ & \\
\hline$>1-\leq 5$ & $18 / 108(16.7)$ & & $9 / 77(11.7)$ & \\
\hline$>5-\leq 10$ & $15 / 194(7.7)$ & & $20 / 161(12.4)$ & \\
\hline$>10$ & $11 / 122(9.0)$ & & $24 / 89(27.0)$ & \\
\hline \multicolumn{5}{|c|}{ Time period of ART initiation } \\
\hline June 2004 - May 2006 & $5 / 27(18.5)$ & 1.00 & $4 / 16(25.0)$ & \\
\hline June 2006 - May 2008 & $7 / 93(7.5)$ & $0.30(0.10-1.00)$ & $6 / 83(7.2)$ & \\
\hline June 2008 - May 2010 & $14 / 146(9.6)$ & $0.42(0.15-1.19)$ & $16 / 125(12.8)$ & \\
\hline June 2010 - May 2012 & $18 / 125(14.4)$ & $0.70(0.26-1.89)$ & $25 / 102(24.5)$ & \\
\hline June 2012 - May 2013 & $1 / 53(1.9)$ & $0.08(0.01-0.69)$ & $6 / 19(31.6)$ & \\
\hline \multicolumn{5}{|l|}{ Baseline CD $4+$ classification $^{\dagger}$} \\
\hline Severe & $25 / 180(13.9)$ & 1.00 & $19 / 138(13.8)$ & 1.00 \\
\hline Advanced & $7 / 107(6.5)$ & $0.46(0.20-1.08)$ & $13 / 82(15.9)$ & $0.91(0.53-1.57)$ \\
\hline Mild & $4 / 63(6.4)$ & $0.44(0.15-1.27)$ & $12 / 50(24.0)$ & $2.09(1.73-2.52)$ \\
\hline Not significant & $9 / 94(9.6)$ & $0.71(0.33-1.53)$ & $13 / 75(17.3)$ & $1.05(0.93-1.18)$ \\
\hline \multicolumn{5}{|l|}{ Anaemia at ART initiation } \\
\hline None & $16 / 174(9.2)$ & 1.00 & $23 / 141(16.3)$ & \\
\hline Mild & $11 / 92(12.0)$ & $1.34(0.62-2.89)$ & $11 / 65(16.9)$ & $1.05(0.96-1.15)$ \\
\hline Moderate/severe & $18 / 178(10.1)$ & $0.96(0.49-1.90)$ & $23 / 139(15.6)$ & $1.05(0.80-1.40)$ \\
\hline \multicolumn{5}{|l|}{ TB at ART initiation } \\
\hline No & $35 / 355(9.9)$ & & $46 / 269(17.1)$ & 1.00 \\
\hline Yes & $10 / 89(11.2)$ & & $11 / 76(14.5)$ & $0.91(0.75-1.11)$ \\
\hline \multicolumn{5}{|l|}{ WHO stage at initiation } \\
\hline I/II & $29 / 283(103)$ & & $39 / 213(18.3)$ & 1.00 \\
\hline III/IV & $16 / 161(9.9)$ & & $18 / 132(13.6)$ & $1.00(0.70-1.41)$ \\
\hline \multicolumn{5}{|c|}{ Anthropometric measurements ${ }^{\ddagger}$} \\
\hline Normal/above normal & $36 / 246(14.6)$ & & $36 / 168(21.4)$ & 1.00 \\
\hline Below normal & $5 / 59(8.5)$ & & $7 / 49(14.2)$ & $0.70(0.46-1.06)$ \\
\hline Missing & $4 / 139(2.9)$ & & $14 / 128(10.9)$ & \\
\hline \multicolumn{5}{|l|}{ NRTI in first regimen } \\
\hline Non-d4T based & $16 / 166(9.6)$ & & 29/114 (25.4) & \\
\hline $\mathrm{d} 4 \mathrm{~T}$ & 29/278 (10.4) & & 28/231 (12.1) & \\
\hline \multicolumn{5}{|l|}{ PI in first regimen } \\
\hline No & $42 / 396(10.6)$ & & $50 / 305(16.4)$ & \\
\hline Yes & $3 / 48(6.3)$ & & $7 / 40(17.5)$ & \\
\hline \multicolumn{5}{|l|}{ Site } \\
\hline $\mathrm{A}$ & $7 / 70(10.0)$ & & $14 / 52(26.9)$ & 1.00 \\
\hline B & $38 / 374(10.2)$ & & $43 / 293(14.7)$ & $0.75(0.61-0.94)$ \\
\hline \multicolumn{5}{|c|}{ 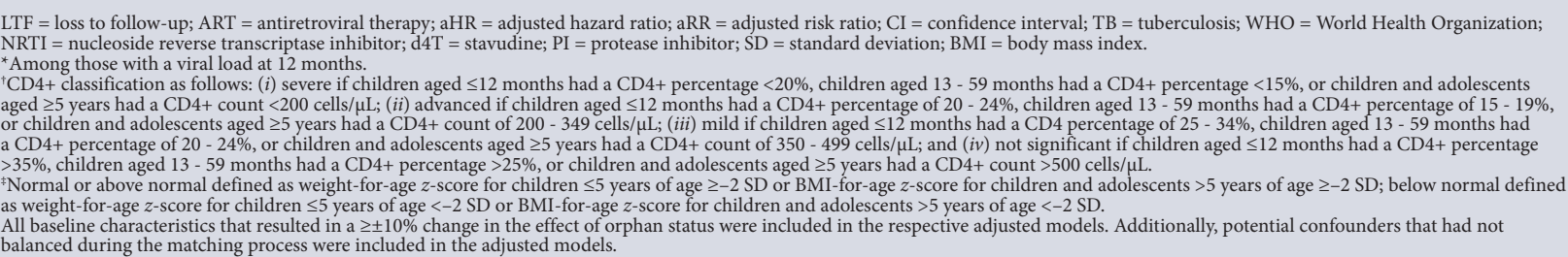 } \\
\hline
\end{tabular}


understanding the reasons for better attrition outcomes for orphans. This analysis only investigated short-term outcomes, resulting in small outcome numbers; longer follow-up may have elucidated additional information. Furthermore, the linkage in the national death register is poor for children, with only an estimated $42 \%$ of deaths that occurred under the age of 1 year recorded in 2007. ${ }^{[29]}$ As such, it is likely that deaths are under-recorded, resulting in underestimation of mortality. Additionally, the researchers could not link the infant, child or adolescent file to parent files to verify parental vital status, resulting in inability to link parents to the death registry to verify orphan status. These data were only from two non-randomly selected urban sites, so results cannot be generalised to children accessing care in non-urban settings.

This study highlights the challenges in conducting outcomes research in clinical settings. There was probably patient self-selection, resulting in our data only comprising children with sufficient family or institutional support to get to care; it is possible that some HIVpositive orphans do not even make it into care before dying, and the ones who do may be healthier, resulting in skewed populations with regard to baseline differences. This possible selection bias may have led to uncontrolled confounding, making it difficult to say whether this bias would be different for orphans v. non-orphans in the general population, as the characteristics of those who did not initiate ART are not known. Despite this, the researchers believe that this clinic-based study still adds to the evidence base and can provide valuable insight for future programming, including highlighting possible predictors of poor treatment outcomes, allowing for targeted early engagement of children and caregivers at initial HIV care and treatment visits.

\section{Conclusions}

Our results show that, once on ART, orphans were less likely than non-orphans to be lost to care (die or be LTF). This result may be because orphans are more integrated into care owing to orphanspecific programming or foster care, or because the orphans in this study were systematically different to the non-orphans in a way that did not allow for the removal of all bias. Understanding the impact of orphan status on ART outcomes could improve targeted strategies, and subsequent treatment and developmental outcomes, for HIV-positive infants, children and adolescents. Additional research investigating age-specific outcomes as well as care-setting environments and the role of the caretaker will be important to elucidate these effects further.

\section{Declaration. None.}

Acknowledgements. The authors thank the patients and staff at the two study sites for making this work possible.

Author contributions. Conceptualised the study: DE; analysed the data: $\mathrm{CH}, \mathrm{ATB}$; wrote the manuscript: $\mathrm{CH}, \mathrm{DE}$; reviewed the manuscript: $\mathrm{CH}$, DE, ATB, SP, SU, JB, LL, IS, MPF.

Funding. This study has been made possible by the generous support of the American people and the President's Emergency Plan for AIDS Relief (PEPFAR) through the United States Agency for International Development (USAID) under the terms of the Cooperative Agreement 674-A-00-08-0000-700 to Right to Care and Cooperative Agreements AID-674-A-12-00029 and 72067419CA00004 to the Health Economics and Epidemiology Research Office. The contents are the responsibility of the authors and do not necessarily reflect the views of PEPFAR, USAID, the United States Government or the Right to Care Clinics.

Conflicts of interest. None.
1. United Nations Children's Fund (UNICEF). Towards an AIDS-free generation: Children and AIDS Sixth Stocktaking Report, 2013. https://www.unicef.org/publications/files/Children_and_AIDS_Sixth_ Stocktaking_Report_EN.pdf (accessed 25 January 2019).

2. United Nations Children's Fund (UNICEF) South Africa. Biennial Report South Africa 2016. https:// . United Nations Children's Fund (UNICEF) South Africa. Biennial Report South Africa 2016. https://
www.unicef.org/southafrica/SAF_resources_biennialreport2014_2015.pdf (accessed 25 January 2019). Www.unicef.org/southafrica/SAF_resources_biennialreport2014_2015.pdf (accessed 25 January 2019). Shisana O, Rehle T, Simbayi LC, et al. South African National HIV Prevalence, Incidence and Behaviou
Survey, 2012. Cape Town: Human Sciences Research Council, 2014. http://www.hsrc.ac.za/uploads pageContent/4565/SABSSM\%20IV\%20LEO\%20final.pdf (accessed 25 January 2019).

4. Joint United Nations Programme on HIV and AIDS (UNAIDS). UNAIDS country factsheets: South Africa 2016. http://www.unaids.org/en/regionscountries/countries/southafrica (accessed 25 January 2019).

Amoako Johnson F, Padmadas SS, Smith PW. Orphanhood and vulnerability: A conduit to poor child health outcomes in Rwanda. AIDS Care 2010;22(3):314-323. https://doi.org/10.1080/09540120903193682 6. Andrews G, Skinner D, Zuma K. Epidemiology of health and vulnerability among children orphaned and made vulnerable by HIV/AIDS in sub-Saharan Africa. AIDS Care 2006;18(3):269-276. https://doi. org/10.1080/09540120500471861

7. Govender K, Reardon C, Quinlan T, George G. Children's psychosocial wellbeing in the context of HIV/ AIDS and poverty: $\hat{A}$ comparative investigation of orphaned and non-orphaned children living in South Africa. BMC Public Health 2014;14:615. https://doi.org/10.1186/1471-2458-14-615

8. Hallfors DD, Cho H, Rusakaniko S, et al. The impact of school subsidies on HIV-related outcomes among adolescent female orphans. J Adolesc Health 2015;56(1):79-84. https://doi.org/10.1016/j. jadohealth.2014.09.004

9. Kaggwa EB, Hindin MJ. The psychological effect of orphanhood in a matured HIV epidemic: An analysis of young people in Mukono, Uganda. Soc Sci Med 2010;70(7):1002-1010. https://doi.org/10.1016/j. socscimed.2009.12.002

10. Marais L, Sharp C, Pappin M, et al. Community-based mental health support for orphans and vulnerable children in South Africa: A triangulation study. Vulnerable Child Youth Stud 2014;9(2):151-158. https:// doi.org/10.1080/17450128.2013.85534

11. Meghdadpour S, Curtis S, Pettifor A, MacPhail C. Factors associated with substance use among orphaned and non-orphaned youth in South Africa. J Adolesc 2012;35(5):1329-1340. https://doi.org/10.1016/j. adolescence.2012.05.005

12. Kikuchi K, Poudel KC, Muganda J, et al. High risk of ART non-adherence and delay of ART initiation among HIV positive double orphans in Kigali, Rwanda. PloS One 2012;7(7):e41998. https://doi. org/10.1371/journal.pone.0041998

3. Kikuchi K, Poudel KC, Muganda J, et al. What makes orphans in Kigali, Rwanda, non-adherent to antiretroviral therapy? Perspectives of their caregivers. J Int AIDS Soc 2014;17:19310. https://doi org/10.7448/IAS.17.1.19310

4. Mokgatle MM, Madiba S. The burden of disease on HIV-infected orphaned and non-orphaned children accessing primary health facilities in a rural district with poor resources in South Africa: A crosssectional survey of primary caregivers of HIV-infected children aged $5-18$ years. Infect Dis Poverty sectional survey of primary caregivers of HIV-infected
2015;4:18. https:///oi.org/10.1186/s40249-015-0049-x

15. Ntanda H, Olupot-Olupot $\mathrm{P}$, Mugyenyi $\mathrm{P}$, et al. Orphanhood predicts delayed access to care in Ugandan children. Pediatr Infect Dis J 2009;28(2):153-155. https://doi.org/10.1097/INF.0b013e318184eeeb

16. Nyandiko WM, Ayaya S, Nabakwe E, et al. Outcomes of HIV-infected orphaned and non-orphaned Nyandiko WM, Ayaya S, Nabakwe E, et al. Outcomes of HIV-infected orphaned and non-orphaned
children on antiretroviral therapy in western Kenya. J Acquir Immune Deficienc Syndr 2006;43(4):418children on antiretroviral therapy in western Kenya. J Acq
425. https://doi.org/10.1097/01.qai.0000243122.52282.89

17. Bhattacharya M, Saxena R. Outcome of anti-retroviral treatment in HIV-infected orphans and nonorphans at an ART centre in North India. Paediatr Int Child Health 2012;32(4):228-232. https://doi org/10.1179/2046905512Y.0000000035

18. Huy BV, Teeraananchai S, Oanh LN, et al. Impact of orphan status on HIV treatment outcomes and retention in care of children and adolescents in Asia. J Virus Erad 2016;2(4):227-231. http:// viruseradication.com/journal-details/Impact_of_orphan_status_on_HIV_treatment_outcomes_and retention_in_care_of_children_and_adolescents_in_Asia/ (accessed_4 February 2019).

19. National Department of Health, South Africa. National Antiretroviral Treatment Guidelines. 2004. http:// apps.who.int/medicinedocs/documents/s17758en/s17758en.pdf (accessed 25 January 2019).

20. National Department of Health, South Africa. South African Antiretroviral Treatment Guidelines 2010 2010. http://apps.who.int/medicinedocs/documents/s19153en/s19153en.pdf (accessed 25 January 2019).

21. National Department of Health, South Africa. South African Antiretroviral Treatment Guidelines 2013. 2013. https://sahivsoc.org/Files/2013\%20ART\%20Treatment\%20Guidelines\%20Final\%2025\%20 March\%202013\%20corrected.pdf (accessed 25 January 2019).

22. United Nations Children's Fund (UNICEF). Orphans. https://www.unicef.org/media/media_45279.html (accessed 25 January 2019).

23. Mayo Clinic. Division of Biomedical Statistics and Informatics. GMATCH. http://bioinformaticstools. mayo.edu/research/gmatch/ (accessed 10 July 2019).

24. Fox MP, Brennan A, Maskew M, MacPhail P, Sanne I. Using vital registration data to update mortality Fox MP, Brennan A, Maskew M, MacPhail P, Sanne I. Using vital registration data to update mortality
among patients lost to follow-up from ART programmes: Evidence from the Themba Lethu Clinic, South among patients lost to follow-up from ART programmes: Evidence from the Themba Lethu Clinic, So
Africa. Trop Med Int Health 2010;15(4):405-413. https://doi.org/10.1111/j.1365-3156.2010.02473.x

Africa. Trop Med Int Health 2010;15(4):405-413. https://doi.org/10.1111/j.1365-3156.2010.02473.x
25. Brennan AT, Maskew M, Sanne I, Fox MP. The importance of clinic attendance in the first six months on

Brennan AT, Maskew M, Sanne I, Fox MP. The importance of clinic attendance in the first six months on
antiretroviral treatment: A retrospective analysis at a large public sector HIV clinic in South Africa. J Int antiretroviral treatment: A retrospective analysis at a large public
AIDS Soc 2010;13:49. https://doi.org/10.1186/1758-2652-13-49

26. Raguenaud ME, Isaakidis P, Zachariah R, et al. Excellent outcomes among HIV+ children on ART, but unacceptably high pre-ART mortality and losses to follow-up: A cohort study from Cambodia. BMC Pediatr 2009;9:54. https://doi.org/10.1186/1471-2431-9-54

27. Magadi MA. Household and community HIV/AIDS status and child malnutrition in sub-Saharan Africa: Evidence from the demographic and health surveys. Soc Sci Med 2011;73(3):436-446. https://doi. org/10.1016/j.socscimed.2011.05.042

28. Akwara PA, Noubary B, Lim Ah Ken P, et al. Who is the vulnerable child? Using survey data to identify children at risk in the era of HIV and AIDS. AIDS Care 2010;22(9):1066-1085. https://doi.org/10.10 80/09540121.2010.498878

29. Nannan N, Dorrington R, Laubscher R, et al. Under-5 Mortality Statistics in South Africa: Shedding Some Light on the Trends and Causes 1997 - 2007. Cape Town: MRC Burden of Disease Rsearch Unit, 2012. http://www.mrc.ac.za/sites/default/files/files/2017-05-26/MortalityStatisticsSA.pdf (accessed 25 January 2019).

30. World Health Organization. Interim WHO clinical staging of HIV/AIDS and HIV/AIDS case definitions for surveillance: African Region. 2005. https://www.who.int/hiv/pub/guidelines/clinicalstaging.pdf?ua=1 for surveillance: African

31. World Health Organization. Haemoglobin concentrations for the diagnosis of anaemia and assessment of . World Health Organization. Haemoglobin concentrations for the diagnosis of anaemia and asse
severity. 2011. http://www.who.int/vmnis/indicators/haemoglobin.pdf (accessed 10 July 2019).

32. World Health Organization. WHO child growth standards. 2006. https://www.who.int/childgrowth/en/
3. 2011. http://www.who.int/vmnis/indicators/haemoglobin.pdf (accessed 10 July 2019). World Health Organiza
(accessed 10 July 2019)

33. World Health Organization. Nutrition Landscape Information System (NLIS) country profile indicators interpretation guide. 2010. https://www.who.int/nutrition/nlis_interpretation_guide.pdf (accessed 10 July 2019). 